\title{
Colorectal Neuroendocrine Tumor by AJCC v8 Stage
}

National Cancer Institute

\section{Source}

National Cancer Institute. Colorectal Neuroendocrine Tumor by A/CC v8 Stage. NCI

Thesaurus. Code C135205.

A term that refers to the staging of a colorectal neuroendocrine tumor, following the rules of the TNM AJCC V8 classification system. This staging system applies to colorectal "carcinoid" tumors (neuroendocrine tumor G1 and G2, and rare-well differentiated G3). High-grade neuroendocrine carcinomas and mixed adenoneuroendocrine carcinomas of the colon and rectum are not staged using this staging system. (from AJCC 8th Ed.) 